\title{
Comparison of the frequency of dental caries in asthmatic children under treatment with inhaled corticosteroids and healthy children in Sabzevar in 2017-2018
}

\author{
Kazem Hassanpour ${ }^{1}$, Human Tehrani ${ }^{1}$, Maryam Goudarzian ${ }^{2}$, Sarah Beihaghi ${ }^{3}$, Mina Ebrahimi ${ }^{1}$, Parastoo Amiri ${ }^{4}$
}

\begin{abstract}
Background and Objective: Regarding the prevalence of premature dental caries in childhood and the role of asthma as a risk factor for increased vulnerability to dental caries, the present study aimed to determine and compare the frequency of dental caries between asthmatic children under treatment with inhaled corticosteroids and healthy children.

Methodology: In this case-control study, 70 children with asthma who were taking corticosteroid sprays for at least one year and 70 healthy children aged 3-12 visiting the clinic or office of pediatricians in 2017-2018 were selected as the sample based on convenient sampling method. Clinical examination for the diagnosis of dental caries was conducted using the decayed-missing-filled teeth (DMFT) index. The obtained data were statistically analyzed in SPSS-18.

Results: The mean score of DMF index, in each of the subscales of decayed teeth $(D / d)$, missing teeth $(M / m)$, and filled teeth ( $F / f)$, was higher in asthmatic children compared to healthy children $(p<0.05)$.

Conclusion: The study findings suggest that it is necessary to pay a special attention to prevention programs including increasing the awareness of parents and training in strategies for the reduction of complications of drugs and providing organized dental care and services, especially for asthmatic children who are at greater risk of dental caries.
\end{abstract}

Keywords: asthmatic children, inhaled corticosteroid, dental caries, DMF index

\section{INTRODUCTION}

According to the World Health Organization (WHO), asthma is the most common chronic childhood disease with the highest prevalence among children aged 6-11 (1). Previous studies have shown that symptoms related to dental caries in children include Streptococcus mutans, visible dental plaque along with poor oral health, low socioeconomic status, parental educational attainment, oral flora, underlying illnesses, taking some medications, gender, and the ethnic and racial status (2). Therefore, considering the importance of deciduous teeth and their role in proper nutrition and growth of children, beauty and the formation of speech in the early years of life, and, most importantly, and provision of a healthy environment for the growth of permanent teeth, dental caries can indicate a major weakness in the early stages of growth and development of children (3). Asthma is a chronic respiratory tract syndrome that causes inflammation, irritability, and stenosis (spasm) of the airways of the lung. There is no definite treatment of asthma and its control only aims to reduce the inflammation of airways and opening the respiratory tracts. The disease control is based on pharmaceutical and non-pharmaceutical methods (4). As the basis of asthma treatment, drug therapy refers to the use of two groups of drugs including anti-inflammatory drugs and bronchodilators. The use of corticosteroids as an aerosol inhaler is one of the effective treatments for asthma using anti-inflammatory drugs. However, this drug causes complications such as throat and tongue irritation, reduced saliva, mouth and throat candidiasis, thirst, and dry mouth.

\footnotetext{
Sabzevar university of medical sciences, Sabzevar, Iran

2 Iranian Research Center on Healthy Aging, Sabzevar University of Medical Sciences, Sabzevar, Iran

3 General Dentist, Sabzevar university of medical sciences, Sabzevar, Iran

4 Department of Health and Community Medicine, Shahid Beheshti University of Medical Sciences, Tehran, Iran
}

Correspondence: Parastoo Amiri

Department of Health and Community Medicine, Shahid Beheshti University of Medical Sciences, Tehran, Iran

E-mail:Amiri.Parasto@gmail.com

Received: 3 Mar 2018, Accepted: 21 April 2018

(C) 2019 by the authors; licensee Modestum Ltd., UK. This article is an open access article distributed under the terms and conditions of the Creative Commons Attribution License (http://creativecommons.org/licenses/by/4.0/). 
Another group of drugs is inhaled bronchodilators which are commonly used for the treatment of asthma. Inhaled corticosteroids produce the highest concentration of drug in the airways and maintain its lowest level in the blood (5). Therefore, compared to oral administration, lower doses of inhaled drugs have been taken into account in order to achieve more effective and optimum in the control of asthma. Reduced saliva, dry mouth, and throat irritation are among the complications of inhaled drugs (6). According to recent statistics, the prevalence of asthma has increased over the past decades (7). In moderate to severe asthma cases, in addition to conventional symptoms of the disease, systemic symptoms such as reduced saliva, increased gingivitis, mucosal changes, mouth breathing, and jaw abnormalities are observed in children. Oral complications in children with asthma are caused by the nature of the disease and drug therapy (8). Since 1970, asthma has been introduced as a risk factor for increasing the vulnerability to dental caries. The results of a number of recent studies also indicate a clear relationship between asthma and dental caries (9). By loosening smooth muscles in the oral cavity, agonists of beta-adrenergic and corticosteroid reduce the salivary flow and oral $\mathrm{pH}$ to less than 7. This leads to the inactivation of antibacterial biological agents such as amylase and calcium ions and secretion of immunoglobulin and lysozyme inside the oral cavity, which cause the acceleration and expansion of dental caries $(1,10)$. Moreover, the low awareness of the proper use of inhalable sprays can increase the risk of tooth decay because of the long-term maintaining of the drug inside the mouth (11). Many studies have shown the relationship between asthma and dental caries. Given the prevalence of this disease and also considering the fact that oral health is part of the social component of health, the present study aims to determine and compare the frequency of dental caries between asthmatic children under treatment with inhaled corticosteroids and healthy children.

\section{METHODOLOGY}

The present research was a case-control study whose population consisted of children with asthma and healthy children aged 3-12 visiting the clinic or office of pediatricians during the process of data collection by the author. Given the limited number of samples examined, the convenient sampling method was used in this study. Accordingly, all children with asthma diagnosed by a pediatrician based on clinical and radiographic criteria were assigned to the case group and healthy children according to medical records and confirmation of the absence of respiratory and other systemic diseases by a pediatrician were assigned to the control group. The inclusion criteria were the history of treatment with inhaled corticosteroids for at least one year for asthmatic children, non-affliction with other systemic diseases in both groups, non-use of other medications, no history of taking antibiotics during the last month, and no history of oral and dental traumas. On the other hand, individuals with therapeutic traumas were excluded from the study. A consent form was obtained from parents of children for participation in the study. Considering a confidence level of $95 \%$ and a test power of $80 \%$, the sample size was determined to be 70 . The required data were collected using a questionnaire and interview. The demographics questionnaire consisted of items about gender, weight, date of birth, parental educational attainment, and father's name. In addition, information about the duration of affliction with asthma, duration of taking drugs, type of spray, the use of milk bottle or pacifier, nutritional conditions, and toothbrushing status was collected through interview with parents of children or review of their medical records. DMFT index was used for the assessment of oral and dental health. This index measures the oral health in four subscales including the number of decayed teeth, the number of missed teeth, the number of filled teeth, and total number of teeth. To calculate DMFT index, total number of decayed, missed, and filled teeth are counted separately and their mean is calculated. DMFT index is an international standard for the assessment of the oral health of deciduous and permanent teeth which was developed by WHO in $1931(12,13)$ and is commonly used in different studies to examine the oral health of people $(7,14-16)$. As the best epidemiological indicator in dentistry, this index indicates the oral health status of people in four subscales of decayed, missed, filled, and total teeth. Before the beginning of the research, the participants were briefed on the study objectives and procedure and then their oral health status was examined by a dentist. To determine DMFT index, the number of decayed (D), missed $(M)$, and filled $(F)$ teeth was counted and the mean of them was calculated. Then, the results were compared with the data obtained from healthy children and reported as mean scores. In order to evaluate the results of DMFT index, the scores were classified into 5 levels of very low (0-1.1), low (1.2-2.6), moderate (2.7-4.5), high (4.6-6.5), and very high (more than 6.6). The data were statistically analyzed using chi-square, Fisher's exact test, and t-test in SPSS-18. 
Table 1: The mean duration of affliction with asthma and duration of using corticosteroid-containing sprays among asthmatic children

\begin{tabular}{lcc}
\hline Variable & Mean & Standard deviation \\
\hline Duration of affliction with asthma & 2.49 & 1.024 \\
\hline Duration of using corticosteroid-containing sprays & 1.90 & 1.151 \\
\hline
\end{tabular}

Table 2: The mean and standard deviation of DMFT index in the two groups of asthmatic and healthy children

\begin{tabular}{|c|c|c|c|}
\hline \multicolumn{2}{|c|}{ DMFT index } & Mean & Standard deviation \\
\hline \multirow{2}{*}{ Decayed teeth } & Asthmatic children & 2.41 & 1.26 \\
\hline & Healthy children & 1.62 & 0.833 \\
\hline \multicolumn{2}{|c|}{ Test result } & \multicolumn{2}{|c|}{ t-test $/ p$-value $=0.001$} \\
\hline & Asthmatic children & 1.13 & 0.833 \\
\hline Missed teeth & Healthy children & 0.67 & 0.7 \\
\hline \multicolumn{2}{|c|}{ Test result } & \multicolumn{2}{|c|}{ t-test $/ \mathrm{p}$-value $=0.009$} \\
\hline & Asthmatic children & 0.96 & 0.806 \\
\hline Filled teeth & Healthy children & 0.51 & 0.682 \\
\hline \multicolumn{2}{|c|}{ Test result } & \multicolumn{2}{|c|}{ t-test $/ \mathrm{p}$-value $=0.014$} \\
\hline \multirow[b]{2}{*}{ DMFT } & Asthmatic children & 0.71 & 1.47 \\
\hline & Healthy children & 0.48 & 1.002 \\
\hline \multicolumn{2}{|c|}{ Test result } & \multicolumn{2}{|c|}{ t-test $/ \mathrm{p}$-value $=0.002$} \\
\hline \multirow{3}{*}{$\mathrm{dmft}$} & Asthmatic children & 3.79 & 1.83 \\
\hline & \multirow[t]{2}{*}{ Healthy children } & 2.32 & 1.21 \\
\hline & & \multicolumn{2}{|c|}{ t-test $/ p$-value $=0.001$} \\
\hline
\end{tabular}

\section{RESULTS}

The study findings show that there was no significant difference between the two groups of asthmatic and healthy children in terms of background variables and gender, the use of milk bottle or pacifier, the use of milk powder or breast milk, toothbrushing status, parental educational attainment, father's job, and age group $(p>0.05)$. According to Table 1 , the mean duration of affliction with asthma and the mean duration of using corticosteroid-containing sprays among asthmatic children are equal to $2.49 \pm 1.024$ and $1.90 \pm 1.151$, respectively.

Based on the results presented in Table 2, the mean number of decayed, missed, and filled teeth and the mean DMFT index in children with asthma, who had the history of using corticosteroid-containing sprays for 2 years, were significantly higher than healthy children $(p<0.05)$.

\section{DISCUSSION}

The results of this study indicated that the mean number of decayed, missed, and filled teeth and the mean DMFT index in children with asthma was higher than healthy children. In addition, there was a significant difference between the two groups in terms of each subscale of DMFT index, as the mean of the mean number of decayed, missed, and filled teeth and the mean DMFT index in children with asthma, who had the history of using corticosteroid-containing sprays for 2 years, were significantly higher than healthy children. Klink et al. (2016) reported that the mean score of decayed, missed, and filled teeth in asthmatic and healthy children were equal to $3.65 \pm 2.35$ and $1.76 \pm 1.25,0.33 \pm 0.09$ and $0.02 \pm 0.14$, and $0.33 \pm 0.09$ and $1.25 \pm 0.69$, respectively. Their findings also indicated that tooth decay has no significant relationship with the dose and duration of taking medications $(p>0.05)(17)$. The results of the present study are consistent with the findings of Klink et al. in terms of the mean score of decayed, missed, and filled teeth but inconsistent in the significant relationship of the mean scores with the dose and duration of taking medications.

In another study conducted by Chelia et al. (2016), it was shown that the mean score of decayed, missed, and filled teeth in asthmatic children $(4.53 \pm 3.38)$ was higher than healthy children $(1.58 \pm 1.51)(18)$. This is consistent with the findings of the present study. By contrast, the results of the present study are not consistent with the findings of Ehsani et al. (2013) (19) who reported that there is no significant relationship between asthma and oral health and this disease does not increase the risk of dental caries. Considering the conflicting results of studies mentioned above, it cannot be conclusively hypothesized that dental carries are more prevalent in asthmatic children than healthy ones. However, these conflicting results may be attributed to the low volume of samples studied, differences between anti-asthma drugs, and the difference in the severity of asthma among the samples. Tooth decay is the most common chronic disease of childhood. Although the prevalence of dental caries has generally reduced, it is still a major health problem in developing 
countries and even in advanced countries (20). On the other hand, the high mean score of dental caries index (D) in children with asthma in above-mentioned studies can be due to the incorrect pattern of using corticosteroid drugs and mouth breathing. Given the inattention to this point in previous studies, it can be mentioned more confidently as the main risk factor for increased dental caries in children with asthma. Missed teeth (M) is another subscale of DMFT index. The high mean of this index in both groups of asthmatic and healthy children in this study and other studies mentioned above (more than 1 according to WHO criteria) may suggest the inattention of parents to the growth of deciduous and permanent teeth and their low awareness of the importance of oral health and nutritional patterns (sugary food consumption) of their children. This causes the early decay of the first permanent molar tooth, which is the most important tooth in chewing and generally the health of other teeth, because the growth of this tooth influences the way other teeth grow (21).

The results of the present study generally indicated that the mean $\mathrm{dmft}$ index was equal to 3.79 in asthmatic children and 2.19 in healthy children. In addition, the mean DMFT index was obtained 0.71 and 0.48 for asthmatic and healthy children, respectively. These figures demonstrate the higher mean of $\mathrm{dmft}$ in asthmatic children than healthy ones. Therefore, there is a significant difference between the two groups in terms of the mean dmft/DMFT index $(p<0.05)$, as the mean dmft/DMFT index in children with asthma, who had the history of using corticosteroid-containing sprays for 2 years, were significantly higher than healthy children. Accordingly, it can be hypothesized that taking of anti-asthma inhaled corticosteroids can affect the overall mean of dmft/DMFTT index in asthmatic children. Mohammad Hamid et al. (2017) reported that there is no significant relationship between taking inhaled drugs and dental caries in asthmatic children ( $p>0.05$ ). This is consistent with the findings of the present study about the high mean of DMFT index of children with asthma (7). In a study conducted by Santos et al. (2012), no significant relationship was found between taking antiasthma drugs (inhaled corticosteroids) and the mean score of DMFT index ( $p>0.05)$ (22). This result is consistent with the findings of the present study.

Considering the results of the present study and comparing it with the results of other studies mentioned above, it can be stated that there is no consensus among specialists on the effects of asthma on oral health (23). One of the possible reasons for the conflict between results of different studies on this subject may be the difference in asthma severity and type of medications taken by patients. For instance, some studies have shown that the use of syrups, due to the presence of sugar in their ingredients and its high concentration, is associated with higher prevalence of dental caries (24). Assessing the studies conducted in this area, it can be emphasized that many of the factors that may affect oral health were not taken into account altogether in these studies. Most of these focused on the socioeconomic and individual homogeneity of children and neglected some factors such as previous training in the use of toothbrush, the use of mouthwash after taking medications, daily sugar intake, and the number of annual dentistry visits. It is noteworthy that since dental decay is a multifactorial illness, these factors should be taken into account altogether in future studies.

\section{CONCLUSION}

Based on the study findings, it is recommended to provide prevention programs and organized dental care and services in order to promote the oral health of asthmatic children. In addition, diet improvement, emphasis on cutting down on sugars and regular visit of children to dentistry, encouragement of using toothbrush, dental floss, and fluoridecontaining mouthwash, and training in the correct and proper use of inhaled corticosteroid sprays should be taken into account in this regard.

\section{ACKNOWLEDGEMENTS}

The present paper was extracted from a dissertation for obtaining a doctoral degree in general medicine. The authors would like to thank Deputy of Research and Technology of University of Medical Sciences, managers of affiliated hospitals and clinics, and families who patiently helped us in this research.

\section{REFERENCES}

1. Ektah K, Arun RJ, Elza T. Oral findings in asthmatic children. J Amr Med. 2014;10(1):1-44.

2. Shulman JD, Taylor SE, Nunn ME. The association between Asthma and Dental Caries in Children and Adolescents: A Population-Based Case-Control Study. Caries Res. 2001;35:240-6. https://doi.org/10.1159/000047464 PMid:11423718 
3. Ersin NK, Gulen F, Ernot N, Cogula D, Demir E, Tanac R, Aydemir S. Oral and Dental Manifestations of young Asthmatics Related to Medication, Severity and Duration of Condition. Pediatrics Int. 2006;48:549-54. https://doi.org/10.1111/j.1442-200X.2006.02281.x PMid:17168972

4. Karova E, Christoff G. Impact of different combinations of in haled corticosteroid and long acting sympathicomimetics on dental health of asthmatic. J lamb. 2012;18:224-8.

5. Stensson M, Wendt LK, Koch G, Oldaeus G, Ramberg P, Birkhed D. Oral health in young adults with long-term, controlled asthma. Acta Odontol Scand. 2011;69:158-64. https://doi.org/10.3109/00016357.2010.547516 PMid:21231815

6. Smidt D, Torpet LA, Nauntofte B, Heegaard KM, Pedersen AM. Associations between labial and whole salivary flow rates, systemic diseases and medications in a sample of older people. Community, Dent Oral Epidemiology. 2010;38:422-35. https://doi.org/10.1111/j.1600-0528.2010.00554.x PMid:20545715

7. Mohamed Hamid S, Elkhadir EF, Hassan A. Dental caries in 3-12 year old Sudanese children with bronchial asthma. J Dent Res Rev. 2017;167-71.

8. Vazquez EM, Vazquez F, Barrientos MC, Cordova JA, Lin D, Beltran FJ, et al. Association between asthma and dental caries in the primary dentition of Mexican children. World J Pediatr 2011;7(4):344-9. https://doi.org/10.1007/s12519-011-0300-x PMid:21633854

9. Golshan M, Mohammad-Zadeh Z, Zahedi Nejad N, Rostam Poor B. Prevalence of asthma and related symptoms in primary school children of Isfahan, Iran, in 1998. Asian Pac J of Allergy Immunol. 2001;19:163-70. PMid: 11826910

10. Paganini M, Dezan C, Bichaco T, de Andrade F, Neto A, Fernandes K. Dental caries status and salivary properties of asthmatic children and adolescents. Int J Paediatr Dent. 2011;21(3):185-91. https://doi.org/10.1111/j.1365263X.2010.01109.x PMid:21281365

11. Stensson M, Wendt LK, Koch G, Oldaeus G, Birkhed D. Oral health in preschool children with asthma. Int J Paediatr Dent. 2008;18:24350. https://doi.org/10.1111/j.1365-263X.2008.00921.x PMid:18489575

12. Çolak H, Dülgergil ÇT, Dalli M, Hamidi MM. Early childhood caries update: A review of causes, diagnoses, and treatments. J Nat Sci Biol Med. 2013;4(1):29-38. https://doi.org/10.4103/0976-9668.107257 PMid:23633832 PMCid:PMC3633299

13. Twetman S. Caries prevention with fluoride toothpaste in children: an update. Eur Arch Paediatr Dent. 2009;10(3):162-8. https://doi.org/10.1007/BF03262678 PMid:19772846

14. Heidari A, Seraj B, Shahrabi M, Maghsoodi H, Kharazifard MJ, Zarabian T. Relationship Between Different Types and Forms of Anti-Asthmatic Medications and Dental Caries in Three to 12 Year Olds. J Den Med Sci 2016;13(4):238-43.

15. Khalifa MA, Abouelkheir HM, Khodiar SE, Mohamed GA. Salivary composition and dental caries among children controlled asthmatics. J Egyp Chest Dis and Tubs. 2014;63(4):777-88. https://doi.org/10.1016/j.ejcdt.2014.05.003

16. Wongkamhaeng K, Poachanukoon O, Koontongkaew S. Dental caries, cariogenic microorganisms and salivary properties of allergic rhinitis children. Inter J of Ped Otorh. 2014;78:860-5. https://doi.org/10.1016/j.ijporl.2014.03.001 PMid:24679591

17. Kilinc $G$, Uzuner $N$, Karaman O. Effect of dental care programmer and fluoridation in the prevention of dental caries in asthmatic children. J Pak Med Assoc. 2016;66(11):1378-84. PMid:27812052

18. Chellaih P, Sivas's G, Chintu S, Vedam V, Arunachalam R, Sarsu M. Effect of anti-asthmatic drugs on dental health: A comparative study. J Pharm Bioallied Sci. 2016;8(1):77-80.

19. Ehsani S, Moin M, Meighani Ghasem, Pourhashemi Jalal, Khayatpisheh Hadi, Yarahmadi Nazli, Oral Health Status in Preschool Asthmatic Children in Iran. J Allergy Asthm immune 2013;12(3):254-61.

20. Pereira SM, Tagliaferro EP, Cortellazzi KL, Ambrosano GM, Mialhe FL, Meneghim Mde C, et al, Estimate of DMFT index using teeth most affected by dental caries in twelve-year-old children. Rev Saude Publica. 2009;43(1):17982. https://doi.org/10.1590/S0034-89102009000100024

21. Mcdonald RE, Avary DR, Stooky GK, Chin JR. Dental Caries in the Child and Adolescent. Ninth ed., Missouri, Mosby Elsevier. 2011:184. https://doi.org/10.1016/B978-0-323-05724-0.50014-X

22. Santos NC, Jamelli S, Costa L, Baracho FC, Medeiros D, Rizzo JA, Sarinho E, assessing caries, dental plaque and salivary flow in asthmatic adolescents using inhaled corticosteroids. Allerg et immune. 2012;40(4):220-4. 
23. Namal N, Yüceokur A, Can G. Significant caries index values and related factors in 5-6-year-old children in Istanbul, Turkey. East Mediterr Health J. 2009;15(1):178-84. PMid:19469441

24. Botelho MP, Maciel SM, Cerci NA, Dezan CC, Fernandes KB, de Andrade FB. Cariogenic microorganisms and oral conditions in asthmatic children. Caries Res. 2011;45(4):386-92. https://doi.org/10.1159/000330233 PMid:21822017

$$
\diamond \diamond \diamond \diamond \diamond \diamond \diamond
$$

http://www.ejgm.co.uk 